\title{
Tea Seed Oil Alleviates Metabolic Derangement and Oxidative Stress in Rats Fed with High Fat and High Fructose Diet
}

\author{
Warinna Pinthong ${ }^{1}$ and Thamolwan Suanarunsawat ${ }^{2 *}$
}

\begin{abstract}
${ }^{1}$ Physiology Unit, Department of Medical Sciences, Faculty of Science, Rangsit University, Pathumtani 12000, Thailand

${ }^{2}$ Research Facilitation Division, Faculty of Medicine Vjira Hospital, Navamindradhiraj University, Bangkok 10300, Thailand

*Corresponding author. E-mail: tmw706@gmail.com https://doi.org/10.12982/CMUJNS.2020.0043
\end{abstract}

Received: August 6, 2019

Revised: October 29, 2019 Accepted: November 29, 2019

\begin{abstract}
Tea seed oil (TSO) has been shown to exert therapeutic effects to treat various diseases. However, no experimental evidence is available to support its actions on metabolic derangement, and antioxidant effects to protect-risk organs against a high fat high fructose (HFHF) diet. The various fatty acids in TSO were determined using GC-MS. Three groups of male Wistar rats were used in the present study: normal rats, rats fed with HFHF diet for 12 weeks, and rats fed with $\mathrm{HFHF}$ diet along with TSO. Blood glucose, AUC of glucose, serum insulin, HOMA-IR, serum lipid profile were determined. Liver, kidney and cardiac injuries were evaluated. Lipid peroxide content and the activities of antioxidant enzymes in the liver, kidney and cardiac tissues were also assessed. Oleic acid was the primary fatty acid in TSO. HFHF diet slightly raised basal blood glucose and HOMA-IR. AUC of glucose, serum lipid profile, and serum levels of $A S T, A L T, L D H, C K-M B$, creatinine and BUN were increased in HFHF-fed rats. TSO decreased AUC of glucose and serum lipid profile whereas it suppressed serum insulin level and HOMA-IR. The high levels of AST, ALT, LDH, CK-MB, creatinine and BUN were also normalized. TSO also suppressed the high levels of TBARS and enhanced the activities of antioxidant enzymes in the liver, cardiac and renal tissues. It can be concluded that TSO exerted anti-hyperglycemic and anti-hyperlipidemic activities as well as improved insulin sensitivity. It had free radical scavenging effect providing organ protection against HFHF diet feeding.
\end{abstract}

Keywords: Tea seed oil, Metabolic syndrome, Oleic acid, Antioxidant enzyme activity 


\section{INTRODUCTION}

In the modern life style, consumption of a diet rich in fat and/or refined carbohydrates like fructose coupled with less physical activity significantly contributes to hyperglycemia, dyslipidemia, fatty liver, cardiovascular damage and obesity, which ultimately leads to metabolic syndrome (Poudyal et al., 2012; Ramli et al.,2014; Lozano et al., 2016; McCracken et al., 2018). The prevalence of patients with hyperglycemia and dyslipidemia is continuously increasing and is expected to become a health problem especially in developing countries (Poudyal et al., 2012; de Castro et al., 2013; Misra and Khurana., 2008 ) since they are the primary causes of subsequent various serious body dysfunctions especially the liver, kidney, and cardiovascular systems (Poudyal et al., 2012; de Castro et al., 2013; Ramli et al.,2014; McCracken et al., 2008). Several interventions have been recommended to prevent and/or treat dyslipidemia and hyperglycemia including smoking cessation, limiting alcohol consumption, increasing physical activity, and controlling diet. However, these interventions are not successful because of the life styles changes. Therefore various drugs with anti-hyperglycemia, anti-hyperlipidemia or anti-obesity properties are widely used. Among these drugs especially anti-obesity drugs have been withdrawn from the market because of serious adverse effects (Kang and Park., 2012; Daneschvar et al., 2016). Similarly, hypolipidemic and hypoglycemic drugs have been found to cause several adverse effects particularly liver damage or hypoglycemic shock when they are used for prolonged periods. Therefore medicinal food or compounds derived from natural products with minimal or no side effects have gained acceptance during the last few years (Ramli et al.,2014; Zouari et al., 2016; Fazel et al., 2008). There are several kinds of medicinal plants with hypolipidemic, hypoglycemic and antioxidant activities. One of those herbs is tea seed which is enriched with tea seed oil (TSO). TSO is a fixed oil which is mainly extracted from the seeds of Camellia oleifera Abel. It is extensively used as cooking oil in several countries including China, Taiwan and Thailand. TSO contains multifarious functional nutrients such as flavonoid, phenolic compounds, unsaturated fatty acids and vitamin $E$ which are highly valuable for health (Fazel et al., 2008; He et al., 2011; Wang et al., 2017). Besides cooking oil, TSO has been used as traditional medicine to prevent and/or cure various diseases including hyperlipidemia, hypertension, coronary heart diseases, atherosclerosis, gastric ulcer, and hepatic damage. It also exhibits antiinflammatory, antimicrobial, antitumor activities as well as improving immunity (He et al., 2011; Cheng et al., 2015; Xiao et al., 2017). Moreover, TSO has been found to have a high natural antioxidant activity (Lee and Yen., 2006; He et al., 2011; Wang et al., 2017; Xiao et al., 2017), and exerted hepatoprotective effects against various stress conditions including hyperlipidemia, toxic agent and 
obstructive jaundice (Lee et al.,2007; Huang et al., 2011; Yang et al., 2013; Cheng et al., 2015).

Numerous findings have reported that a diet with high fat or high carbohydrate like fructose or combination of high fat and high carbohydrate induced metabolic derangement in several animal models (Poudyal et al., 2012; de Castro et al., 2013; Lee et al.,2015; Zouari et al., 2016). However, metabolic derangement has been found to be more prominent in animals fed with a combination of a high fat and high carbohydrate diet (Crescenzo et al.,2014; Ramli et al.,2014; Lee et al.,2015; Lozano et al., 2016; McCracken et al., 2018). Previous experiments examined the effects of TSO on metabolic dysregulations under high fat diet feeding (Huang et al., 2011; Yang et al.,2013; Shen and Wu.,2017). There is no experimental evidence to support its actions on blood glucose and serum lipid in subjects fed with a high fat and high carbohydrate diet. Furthermore no experimental studies investigated its antioxidant activity to protect risk organs including liver, heart and kidney against high fat and high carbohydrate feeding. Therefore the aim of the present study is to elucidate the potential activities of TSO to lower blood glucose and serum lipid profiles, and also antioxidant capacity to protect risk organs in rats fed with high fat and high carbohydrate diet.

\section{MATERIALS AND METHODS}

\section{Identification of fatty acids in tea seed oil}

The tea seed oil (TSO) was purchased from Lamsoon, Ltd, Thailand. TSO was imported from Chaina where TSO was mainly extracted from Camellia oleifera (C. oleifera) seed. Fatty acids contained in TSO were identified using Gas Chromatography-Mass Spectrometry (GC-MS). Fatty acids containing in TSO were transformed into methyl ester (FAMEs). The FAMEs were analyzed by gas chromatography Mass Spectrometry (GC-2010+AOC20i, SHIMADZU), equipped with a flame ionization detector (Electron-Impact mass spectrometry). The temperature of the detector was set at $300^{\circ} \mathrm{C}$. The carrier gas was helium at split ratio 50:1, flow rate was $62.9 \mathrm{~mL} / \mathrm{min}$. The content of fatty acids was expressed as a percentage of the total fatty acids.

\section{Animal preparation}

Male Wistar rats weighing between 180-220g (8-10 weeks old) from the National Laboratory Animal Centre, Mahidol University, Salaya, Nakornprathom, Thailand were used in the study. The animals were housed in the animal facility of the Faculty of Sciences, Rangsit University under standard conditions of temperature $\left(25 \pm 2^{\circ} \mathrm{C}\right), 50-60 \%$ of humidity and $12 \mathrm{hr} / 12 \mathrm{hr}$ light/dark cycles. Food and water were given ad libitum. All animals were cared for in accordance with the principles and guidelines of the Institutional Animal Ethic Committee of Rangsit University (RSEC 05/2012) which is under the 
National Council of Thailand for Animal Care. The animals were randomly divided into three groups of seven rats each as follows:

Group I : normal control rats fed with normal diet and distilled drinking water for 12 weeks

Group II : rats fed with high fat and high fructose (HFHF) diet for 12 weeks.

Group III : rats fed with high fat high fructose (HFHF) diet along with TSO treatment for 12 weeks.

HFHF diet was prepared by adding $2 \mathrm{~g}$ cholesterol powder along with $8.7 \mathrm{~g}$ lard in $100 \mathrm{~g}$ of normal rat diet, and $60 \mathrm{~g}$ fructose was mixed in $100 \mathrm{ml}$ drinking water. Body weight was recorded weekly in all groups. The food composition and energy value were shown in the following.

\begin{tabular}{lcc}
\hline Food ingredients & $\begin{array}{c}\text { Normal diet } \\
(\mathbf{g} / \mathbf{1 0 0} \text { g diet })\end{array}$ & $\begin{array}{c}\text { HFHF diet } \\
(\mathbf{g} / \mathbf{1 0 0} \text { g diet })\end{array}$ \\
\hline crude protein & 24 & 21.3 \\
soy bean oil & 4.5 & 4.0 \\
fiber & 5.0 & 4.4 \\
corn starch & 52.5 & 46.6 \\
mineral mix & 4.3 & 3.8 \\
vitamin mix & 0.3 & 0.3 \\
choline chloride & 0.2 & 0.1 \\
cholesterol powder & - & 2.0 \\
cholic acid & - & 0.6 \\
Lard oil & - & 8.7 \\
moisture & 9.2 & 8.2 \\
Food energy $(\mathrm{kcal} / \mathrm{g})$ & 3.5 & 4.0 \\
Fructose energy in & - & 2.2 \\
drinking water $(\mathrm{kcal} / \mathrm{ml})$ & & \\
\hline
\end{tabular}

For Group III, TSO was orally administered once a day at the dose of 5.69 $\mathrm{g} / \mathrm{kgbody}$ weight/day. This dose has been chosen because of its anti-oxidative effect to protect liver against CCl4 (Lee et al.,2007) and the average dose that lowered blood lipids (Ping et al., 1993; Deng et al.,2002) 


\section{Experimental protocol}

Two series of experiments were carried out.

Determination of blood glucose, oral glucose tolerance tests, serum lipid profile and biochemical evaluation of liver, kidney and cardiac injury

After 12 weeks of normal or HFHF diet feeding, rats were fasted overnight. Blood was collected from rat tails to determine fasting blood glucose (FBG). Homeostasis model assessment of insulin resistance (HOMA-IR) index was calculated by general equation : [(blood glucose $\mathrm{x}$ serum insulin)/405]. Oral glucose tolerance was evaluated by feeding of $2 \mathrm{~g} / \mathrm{kg}$ body weight of $50 \%(\mathrm{~g} / 100$ $\mathrm{ml}$ ) glucose solution. After glucose loading, blood was collected from the tail to determine blood glucose every $30 \mathrm{~min}$ for $120 \mathrm{~min}$. Then area under the curve (AUG) of glucose was calculated.

At the end of experiment, the rats were fasted overnight, and were anesthetized by intraperitoneal injection with sodium pentobarbiturate $(60 \mathrm{mg} / \mathrm{kg}$ body weight). Blood was collected from the abdominal aorta. Serum was separated by refrigerated centrifuge at $3000 \mathrm{rpm}, 4^{\circ} \mathrm{C}$ for $5 \mathrm{~min}$ to determine the serum lipid profile including total cholesterol (TC), triglyceride (TG), high density lipoprotein cholesterol (HDL-C) and low-density lipoprotein cholesterol (LDL-C). Liver damage was evaluated by determination of serum alanine aminotransferase (ALT), aspartate aminotransferase (AST). Cardiac damage was also assessed by determination of serum lactate dehydrogenase (LDH) and creatine kinase $\mathrm{MB}$ subunit (CK-MB). Renal function was evaluated by determination of serum creatinine and blood urea nitrogen (BUN).

\section{Determination of lipid peroxide and antioxidant activities of enzymes in the liver, kidney and cardiac tissues}

At the end of the study, the rats were fasted overnight and were anesthetized by intraperitoneal injection with sodium pentobarbiturate $(60 \mathrm{mg} / \mathrm{kg}$ body weight). Then the jugular vein was cannulated to perfuse ice-cold normal saline to remove the red blood cells. When all organs looked pale, the liver, kidney and heart were isolated, cleaned and weighed. All organs were kept at $80^{\circ} \mathrm{C}$ until further analysis

Determination of tissue lipid peroxide content. All organs were homogenized with $0.1 \mathrm{M}$ phosphate buffer $\mathrm{pH}$ 7.4. Lipid peroxides in the liver, kidney and heart were assessed with thiobarbituric acid reactive substances (TBARS) as previously described (Ohkawa et al.,1979). TBARS was expressed in nmole of malondialdehyde (MDA)/mg protein using 1,1,3,3-tetraethoxy propane as standard. Tissue protein levels were determined by Lowry's method (Lowry et al.,1951).

Determination of tissue antioxidant enzymes activities. Tissue antioxidant enzymes activities including glutathione peroxidase (GPx), catalase (CAT) and superoxide dismutase (SOD) were determined. Liver, kidney and cardiac tissue homogenates were prepared by homogenizing the tissues in a 0.1 $\mathrm{M}$ phosphate buffer $\mathrm{pH}$ 7.4. The homogenate was then centrifuged at 3,000 rpm, 
$4^{\circ} \mathrm{C}$ for $10 \mathrm{~min}$. The supernatant was collected and centrifuged again at 7,800 g, $4^{\circ} \mathrm{C}$ for $30 \mathrm{~min}$. The supernatant fraction was collected and further centrifuged at $136,000 \mathrm{~g}, 4^{\circ} \mathrm{C}$ for $60 \mathrm{~min}$. The final supernatant was then analyzed for estimation of GPx, CAT and SOD activities using the procedures described by Tapple (1978), Luck (1965), and Winterbourn et al (1975) respectively.

\section{Biochemical assay}

Fasting blood glucose (FBG) was determined using an automatic glucometer (Medisense UK Co.,Ltd, Abbott Lab, UK). Serum insulin concentration was determined using rat insulin ELISA kit (Helena Co,Ltd, UK). The serum levels of total cholesterol, triglyceride and HDL-C were assayed by using an enzymatic kit (Ge-sellschaft Für Biochemica und Diagnostica $\mathrm{GmbH}$, Germany). LDL-C was calculated by using the equation: LDL-C $=[$ TC-(HDLC)]-(triglyceride/5). Atherogenic index (AI) was also calculated by equation : AI $=\{$ TC $-($ HDL-C $)\} /($ HDL-C). The serum levels of AST, ALT, creatinine, BUN, $\mathrm{LDH}$ and $\mathrm{CK}-\mathrm{MB}$ were measured using an enzymatic kits (Randox Laboratories, UK).

\section{Statistical Analysis}

All values are presented as mean \pm SEM. The results were analyzed by ANOVA. The Ducan multiple rank test was performed to determine statistical significance among groups by using SPSS software version 16.0. Significant difference was accepted at the level of $P<0.05$.

\section{RESULTS}

\section{Effect of TSO on body weight, food consumption and energy intake}

Both saturated and unsaturated fatty acids were found in TSO as illustrated in Figure 1 and Table 1. The major fatty acid contained in TSO was Oleic acid (83.36\%). No significant difference of body weight between normal and HFHF rats was observed throughout experiment (Figure 2). Body weight of HFHF rats treated with TSO was significantly lower than that of both normal and untreated HFHF rats during the last six weeks. Food intake in HFHF rats treated with or without TSO was lower than that of normal rats throughout experiment (Figure 2). Food consumption of HFHF rats treated with TSO was significantly lower than that of untreated HFHF rats during the last six weeks. Daily energy intake in both groups of HFHF rats were significantly higher than that of normal rats, and it was decreased in rats treated with TSO (Table 2). 


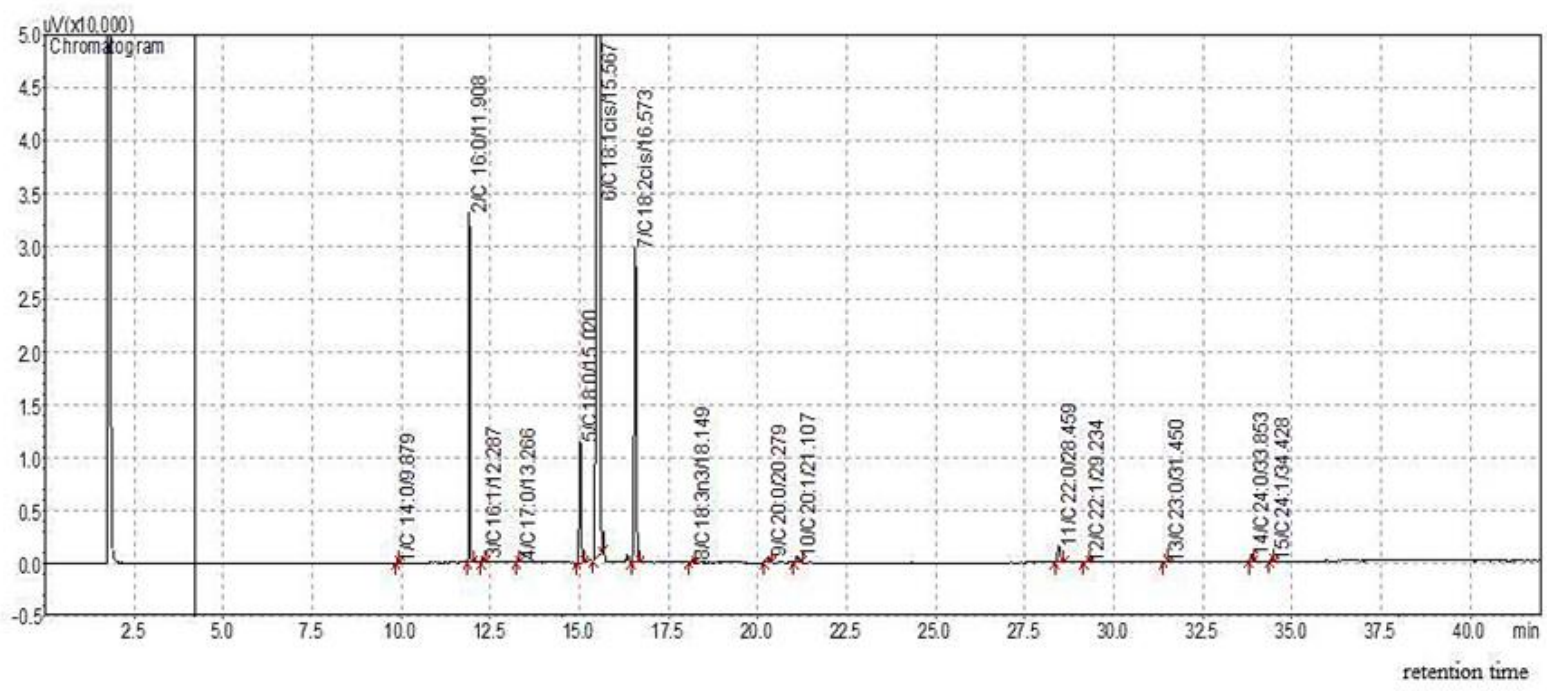

Figure 1. GC chromatogram of fatty acids composition in tea seed oil.

Table 1. Fatty acid compositions in tea seed oil.

\begin{tabular}{lll}
\hline Fatty acid & Molecular formula & $\mathbf{\%}$ \\
\hline Palmitic acid & C $16: 0$ & 4.74 \\
Palmitoleic acid & C $16: 1$ & 0.07 \\
Margaric acid & C $17: 0$ & 0.03 \\
Stearic acid & C $18: 0$ & 2.84 \\
Oleic acid & C $18: 1 \mathrm{n}-9$ cis & 83.36 \\
Linoleic acid & C $18: 2 \mathrm{n}-6$ cis & 7.68 \\
Linolenic acid & C $18: 3 \mathrm{n}-3$ & 0.06 \\
Arachidic acid & C $20: 0$ & 0.18 \\
Behenic acid & C $22: 0$ & 0.55 \\
Erucic acid & C 22:1 n-9 & 0.04 \\
Lignoceric acid & C $24: 0$ & 0.17 \\
Nervonic acid & C $24: 1$ & 0.03 \\
\hline
\end{tabular}



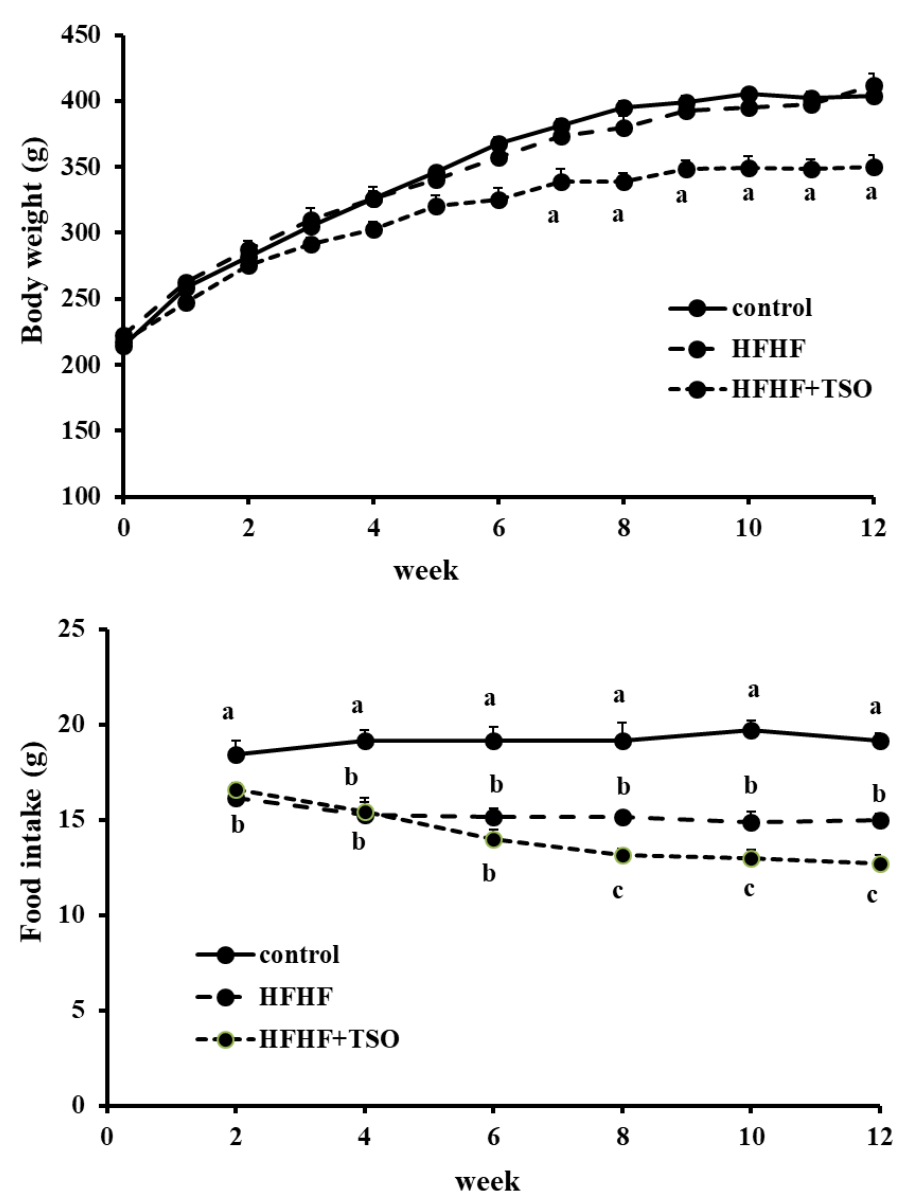

Figure 2. Body weight and food consumption in normal rats and HFHF rats fed with or without tea seed oil (TSO). Values with different superscripts in the same week are significantly different at $P<0.05$. HFHF: high fat and high fructose.

Table 2. Changes of energy intake, basal blood glucose, serum insulin level and homeostatic model assessment of insulin resistance (HOMA-IR) in normal rats, HFHF rat and HFHF rats treated with tea seed oil (TSO).

\begin{tabular}{lcccc}
\hline Group & $\begin{array}{c}\text { Energy } \\
\text { consumption } \\
\text { (kcal/day) }\end{array}$ & $\begin{array}{c}\text { Basal blood } \\
\text { glucose } \\
(\mathbf{m g} / \mathbf{d l})\end{array}$ & $\begin{array}{c}\text { Serum insulin } \\
\text { concentration } \\
(\mathbf{n g} / \mathbf{m l})\end{array}$ & HOMA-IR \\
\hline Control & $67.2 \pm 3.5^{\mathrm{a}}$ & $84.43 \pm 3.14^{\mathrm{a}}$ & $1.11 \pm 0.03^{\mathrm{a}}$ & $0.58 \pm 0.03^{\mathrm{a}, \mathrm{b}}$ \\
HFHF & $100.2 \pm 2.4^{\mathrm{b}}$ & $94.71 \pm 2.85^{\mathrm{a}}$ & $1.10 \pm 0.04^{\mathrm{a}}$ & $0.62 \pm 0.04^{\mathrm{a}}$ \\
HFHF+TSO & $87.7 \pm 2.2^{\mathrm{c}}$ & $90.71 \pm 4.13^{\mathrm{a}}$ & $0.90 \pm 0.02^{\mathrm{b}}$ & $0.51 \pm 0.02^{\mathrm{b}}$ \\
\hline
\end{tabular}

Note: Data are presented as mean \pm SEM. Values with different superscripts in the same column are significantly different at $P<0.05$. HFHF: high fat and high fructose 


\section{Effect of TSO on blood glucose, glucose tolerance, organ weight and serum lipid profile}

Basal blood glucose and HOMA-IR in HFHF rats were slightly raised but it was not statistically significant difference from normal rats (Table 2). For HFHF rats treated with TSO, basal blood glucose was slightly decreased whereas both serum insulin and HOMA-IR were significantly lowered comparing to untreated HFHF rats. Area under the curve (AUC) of glucose in untreated HFHF rats was higher than that of normal rats, and it was significantly suppressed in HFHF rats treated with TSO (Figure 3). The liver and kidney weights of rats treated with or without TSO were significantly higher than that of normal rats (Table 3). No significant difference of heart weight was seen among groups. There were no significant differences of all organs weights in HFHF rats treated with or without TSO. Compared to normal rats, serum total cholesterol, triglyceride, LDL-C and AI were significantly raised whereas HDL-C was decreased in untreated HFHF rats (Table 3). Serum levels of total cholesterol, LDL-C, and AI were decreased whereas the levels of triglyceride and HDL-C were normalized in HFHF rats treated with TSO.

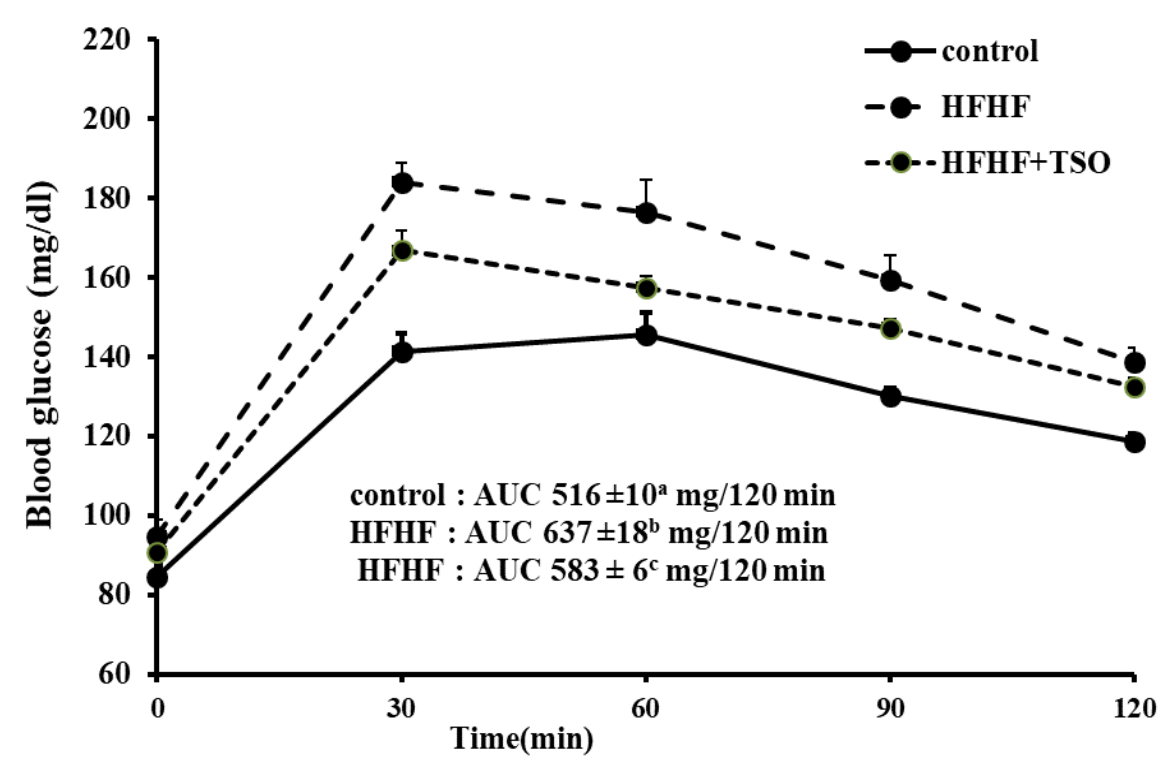

Figure 3. Area under the curve (AUC) of oral glucose tolerance in normal rats, HFHF rats treated with or without TSO. Values are expressed as mean \pm SEM. AUC values with different superscripts are significantly different at $P<0.05$. HFHF: high fat and high fructose. 
Table 3. Organ weight, serum lipid profile and atherogenic index (AI) in normal rats, HFHF rat and HFHF rats treated with TSO

\begin{tabular}{lrcc}
\hline Group & control & HFHF & HFHF+TSO \\
\hline Organ weight $(\mathrm{g} / \mathrm{kgbw})$ & & & \\
$\quad$ Liver & $27.5 \pm 0.9^{\mathrm{a}}$ & $56.0 \pm 3.4^{\mathrm{b}}$ & $57.0 \pm 0.4^{\mathrm{b}}$ \\
Heart & $3.1 \pm 0.1^{\mathrm{a}}$ & $3.1 \pm 0.1^{\mathrm{a}}$ & $3.2 \pm 0.04^{\mathrm{a}}$ \\
Kidney & $4.9 \pm 0.1^{\mathrm{a}}$ & $5.6 \pm 0.1^{\mathrm{b}}$ & $5.5 \pm 0.1^{\mathrm{b}}$ \\
Serum lipid profile & & & \\
(mg/dl) & & & \\
$\quad$ Total cholesterol & $53.9 \pm 5.67^{\mathrm{a}}$ & $157.0 \pm 8.64^{\mathrm{b}}$ & $120 \pm 9.2^{\mathrm{c}}$ \\
$\quad$ Triglyceride & $28.9 \pm 3.6^{\mathrm{a}}$ & $50.0 \pm 5.3^{\mathrm{b}}$ & $21 \pm 2.1^{\mathrm{a}}$ \\
HDL-C & $21.2 \pm 2.0^{\mathrm{a}}$ & $17.5 \pm 1.6^{\mathrm{a}}$ & $18.9 \pm 1.7^{\mathrm{a}}$ \\
$\quad$ LDL-C & $27.0 \pm 3.5^{\mathrm{a}}$ & $130.0 \pm 8.9^{\mathrm{b}}$ & $96.9 \pm 10.1^{\mathrm{c}}$ \\
Atherogenic Index (AI) & $1.54 \pm 0.1^{\mathrm{a}}$ & $8.5 \pm 1.0^{\mathrm{b}}$ & $5.9 \pm 1.1^{\mathrm{c}}$ \\
\hline
\end{tabular}

Note: Values are expressed as mean \pm SEM. Values with different superscripts in each row are significantly different at $P<0.05$. HFHF: high fat and high fructose.

\section{Organ protective and antioxidant activities of TSO}

Table 4 shows the biochemical evaluation of the liver, kidney and cardiac injury. The serum levels of AST, ALT, LDH, CK-MB, creatinine and BUN were augmented in untreated HFHF rats. The high levels of AST, ALT, LDH, CK-MB and BUN were significantly suppressed in HFHF rats treated with TSO. The level of TBARS was higher whereas CAT and SOD activities were lowered without change of GPx activity in the liver tissue of HFHF rats (Table 5). For cardiac tissue, TBARS was raised whereas activities of GPx, CAT and SOD were lowered in HFHF rats. The level of TBARS and all antioxidant enzymes activities were returned to normal levels in both the liver and cardiac tissues of HFHF treated with TSO. For the renal tissue, both the TBAR level and GPx activity were significantly increased without significant change of CAT and SOD activities in untreated HFHF rats. The high level of TBARS returned to the normal level whereas activities of both GPx and SOD were extremely augmented to higher than normal level without change of CAT activity in HFHF rats treated with TSO. 
Table 4. Serum levels of alanine aminotransferase (ALT), aspartate aminotransferase (AST), creatine kinase MB subunit (CK-MB), lactate dehydrogenase (LDH), creatinine and BUN in normal rat, HFHF rat and HFHF rat treated of TSO

\begin{tabular}{lcccccc}
\hline Group & $\begin{array}{c}\text { AST } \\
(\mathbf{U} / \mathbf{L})\end{array}$ & $\begin{array}{c}\text { ALT } \\
(\mathbf{U} / \mathbf{L})\end{array}$ & $\begin{array}{c}\text { CK-MB } \\
(\mathbf{U} / \mathbf{L})\end{array}$ & $\begin{array}{c}\text { LDH } \\
(\mathbf{U} / \mathbf{L})\end{array}$ & $\begin{array}{c}\text { Creatinine } \\
(\mathbf{m g} / \mathbf{d l})\end{array}$ & $\begin{array}{c}\text { BUN } \\
(\mathbf{m g} / \mathbf{d l})\end{array}$ \\
\hline control & $83 \pm 9^{\mathrm{a}}$ & $33 \pm 3^{\mathrm{a}}$ & $581 \pm 40^{\mathrm{a}, \mathrm{b}}$ & $454 \pm 43^{\mathrm{a}}$ & $1.14 \pm 0.03^{\mathrm{a}}$ & $15.24 \pm 0.55^{\mathrm{a}}$ \\
HFHF & $181 \pm 12^{\mathrm{b}}$ & $142 \pm 14^{\mathrm{b}}$ & $757 \pm 58^{\mathrm{b}}$ & $579 \pm 23^{\mathrm{b}}$ & $1.28 \pm 0.04^{\mathrm{b}}$ & $17.79 \pm 0.74^{\mathrm{b}}$ \\
HFHF+TSO & $119 \pm 11^{\mathrm{c}}$ & $54 \pm 6^{\mathrm{a}}$ & $536 \pm 79^{\mathrm{a}}$ & $415 \pm 43^{\mathrm{a}}$ & $1.22 \pm 0.04^{\mathrm{a}, \mathrm{b}}$ & $13.51 \pm 0.76^{\mathrm{a}}$ \\
\hline
\end{tabular}

Note: Values are expressed as mean \pm SEM. Values with different superscripts in each column are significantly different at $P<0.05$. HFHF: high fat and high fructose.

Table 5. Effect of tea seed oil on lipid peroxide and antioxidant enzymes activity in the liver, heart and kidney tissues in HFHF rats.

\begin{tabular}{lccc}
\hline & \multicolumn{3}{c}{ Group } \\
\cline { 2 - 4 } \multicolumn{1}{c}{ Liver } & Normal & HFHF & HFHF+TSO \\
\hline TBARS (nmole MDA/mg protein) & $0.78 \pm 0.05^{\mathrm{a}}$ & $1.94 \pm 0.28^{\mathrm{b}}$ & $0.88 \pm 0.46^{\mathrm{a}}$ \\
GPx ( $\mu$ mole /min/mg protein) & $0.88 \pm 0.12^{\mathrm{a}}$ & $0.86 \pm 0.08^{\mathrm{a}}$ & $0.83 \pm 0.05^{\mathrm{a}}$ \\
CAT ( $\mu$ mole /min / mg protein) & $305 \pm 19^{\mathrm{a}}$ & $244 \pm 36^{\mathrm{b}}$ & $357 \pm 54^{\mathrm{a}}$ \\
SOD (unit /mg protein) & $55 \pm 7^{\mathrm{a}}$ & $37 \pm 3^{\mathrm{b}}$ & $57 \pm 7^{\mathrm{a}}$ \\
$\quad$ & & \\
TBARS (nmole MDA/mg protein) & $0.39 \pm 0.02^{\mathrm{a}}$ & $0.46 \pm 0.02^{\mathrm{b}}$ & $0.37 \pm 0.02^{\mathrm{a}}$ \\
GPx ( $\mu$ mole /mg protein) & $0.36 \pm 0.04^{\mathrm{a}}$ & $0.27 \pm 0.02^{\mathrm{b}}$ & $0.35 \pm 0.01^{\mathrm{a}}$ \\
CAT ( $\mu$ mole /min / mg protein) & $5.86 \pm 0.28^{\mathrm{a}}$ & $4.72 \pm 0.23^{\mathrm{b}}$ & $6.18 \pm 0.54^{\mathrm{a}}$ \\
SOD (unit /mg protein) & $25.40 \pm 2.96^{\mathrm{a}}$ & $16.84 \pm 1.45^{\mathrm{b}}$ & $25.89 \pm 5.26^{\mathrm{a}}$ \\
$\quad$ & & \\
KBidney & & & $0.68 \pm 0.06^{\mathrm{a}}$ \\
GPx ( $\mu$ mole /mg protein) & $0.67 \pm 0.04^{\mathrm{a}}$ & $0.85 \pm 0.06^{\mathrm{b}}$ & $0.96 \pm 0.02^{\mathrm{c}}$ \\
CAT ( $\mu$ mole /min / mg protein) & $0.31 \pm 0.03^{\mathrm{a}}$ & $0.60 \pm 0.04^{\mathrm{b}}$ & $8.54 \pm 0.74^{\mathrm{a}}$ \\
SOD (unit /mg protein) & $34.15 \pm 1.55^{\mathrm{a}}$ & $31.69 \pm 2.27^{\mathrm{a}}$ & $50.31 \pm 6.14^{\mathrm{b}}$ \\
\hline
\end{tabular}

Note: Data are presented as mean \pm SEM. Values with different superscripts in the same row indicate significantly different at $P<0.05$. TBARS, thiobarbituric acid reactive substances ; GPx, glutathione peroxidase; CAT, catalase, ; SOD, superoxide dismutase. HFHF: high fat and high fructose.

\section{DISCUSSION}

It has been widely accepted that energy intake should be balanced with energy expenditure to avoid unhealthy weight gain. Intake of free sugars and total fat to less than $10 \%$ and $30 \%$ respectively of total energy intake has been 
recommended for a healthy diet (WHO., 2003,2015). The prevalence of patients with hyperglycemia and hyperlipidemia has been gradually and continuously increasing because of the modern life style. Several studies have demonstrated that hyperglycemia and hyperlipidemia cause serious health complications such as hypertension, coronary arterial disease, DM, liver diseases (Poudyal et al., 2012; de Castro et al., 2013; Ramli et al.,2014; McCracken et al., 2018). It has been widely known that plants of a herbal origin can play essential roles in treating diverse diseases since they are enriched with bioactive ingredients that might offer effective, safe, and cheap therapy. TSO, commonly used as a cooking oil, has shown its potency as a therapeutic herb. However there is no experimental evidence available regarding its actions on blood glucose, serum lipid profile and its antioxidant effect to protect risk organs against HFHF diet intake. Several lines of evidences demonstrate that body weight of rats fed with HFHF diet was increased whereas food consumption was decreased (Poudyal et al., 2012; Ramli et al.,2014; Lee et al.,2015; Wang et al.,2017). However, our results show that body weight remained normal whereas food intake was decreased in rats fed with HFHF diet for 12 weeks. The same results were also demonstrated in rats fed with HFHF diet for 2 or 8 weeks (Poudyal et al.,2010; Crescenzo et al.,2014). The controversial results might be explained by the different period of HFHF feeding and amount of energy consumption. Several findings reported that despite lower food consumption, body weight was elevated in rats fed with HFHF diet for 13,16,20 or 32 weeks (Poudyal et al., 2012; Ramli et al.,2014; Lee et al.,2015; McCracken et al.,2018). This indicates that prolonged period of HFHF intake is needed to induce higher body weight. Amount of energy intake is another possible cause of body weight elevation. High body weight was apparent in rats with energy intake more than $115 \mathrm{kcal} /$ day (Poudyal et al., 2012; Ramli et al.,2014; Wang et al.,2017; McCracken et al., 2018;) whereas the energy intake in the present study was approximately $100 \mathrm{kcal} /$ day (Table 2) which might not high enough to induce higher body weight. TSO treatment could decrease body weight as well as food intake and energy consumption, suggesting that TSO suppresses food satiety and then finally decreases body weight. Similar observations were also obtained in high-fat fed rats or mice treated with TSO (Yang et al.,2013; Shen and Wu.,2017). This might indicate its potential benefit to lower body weight gain in obesity. The present results show that HFHF feeding significantly raised the liver and kidney weights. Fat deposition and tissue inflammation might be the possible explanation of higher organ weights (de Castro et al.,2013; Nasri et al.,2015; Zouari et al.,2016). However, TSO could not alleviate the higher organ weights.

HFHF diet slightly raised basal blood glucose and HOMA-IR, indicating that HFHF feeding in our study tends to induce insulin resistance. Moreover, HFHF diet impaired glucose tolerance as shown by an increased AUC of glucose (Figure 3). Increased insulin resistance as suggested by several findings is the possible explanation of hyperglycemia in HFHF feeding (Poudyal et al., 2012; 
Lee et al., 2015; Wang et al., 2017; McCracken et al.,2018). Our work showed that TSO treatment slightly reduced basal blood glucose but significantly suppressed serum insulin, HOMA-IR as well as AUC of glucose, implying its capacity to improve insulin sensitivity to enhance glucose disposal. Beside its glucose lowering effect, TSO suppressed high serum lipid profile and AI in rats fed with HFHF diet. Its anti-hyperglycemic and anti-hyperlipidemic effects might be the beneficial property in preventing cardiovascular and liver diseases. It has been reported that vegetable oils enriched with high oleic acid decreased food intake and high serum lipids along with enhanced insulin sensitivity (Ziv et al., 2009; Poudyal et al., 2010; Alkhateeb and Qnais., 2017). Therefore the oleic acid contained in TSO might be responsible for anti-hyperglycemic and anti-hyperlipidemic activities. The possible mechanism of oleic acid to lower blood glucose is to alleviate insulin resistance by promoting GLUT4 translocation in muscle, at least in part, by activating the PI3K pathway (Alkhateeb and Qnais., 2017). Oleic acid has been reported to suppress intestinal cholesterol absorption by down-regulating cholesterol transport-related proteins mRNA (Chen et al., 2011). Moreover oleic acid has been found to diminish plasma lipids by preventing both an increase in the plasma cholesteryl ester transfer protein activity and hepatic LDL receptor suppression along with increased hepatic cholesterol 7 alpha-hydroxylase activity without effect on hepatic HMG CoA reductase activity in hamsters fed with high fat diet (Kurushima et al., 1995).

Several lines of evidences showed that the liver, heart and kidney are the primarily vulnerable organs to oxidative damage produced by diet rich in HFHF (Poudyal et al.,2012; Nasri et al.,2015; Zouari et al.,2016,2017). The present results show that HFHF feeding for 12 weeks impaired the liver and heart tissues as expressed by an augmentation of serum levels of AST, ALT, LDH and CKMB (Table 4).. Previous works demonstrated that a diet rich in HFHF induces oxidative stress, resulting in an increased production of oxygenated free radicals and decreased antioxidant enzymes activities (Poudyal et al., 2010; Wang et., 2017; Zouari et al., 2017). Therefore an augmentation of oxidative stress induced by a HFHF diet in our study might account for both the liver and cardiac injuries as indicated by the elevation of TBARS level and depression of various antioxidant enzymes activities in both tissues (Table 5). It is interesting to note that HFHF feeding in the present study slightly raised serum levels of creatinine and BUN whereas both TBARS and GPx activity were raised without a change of SOD and CAT activities in renal tissue (Table 4,5). This reflects that a HFHF diet feeding in the present study had minimal effect on renal function. The previous study also revealed that kidney structure and function showed only minimal renal injury after 8 months of HFHF feeding (Dissard et al.,2013). An augmentation of renal GPx activity along with high TBARS level in renal tissue might be a renal compensatory response to get rid of excess free radicals produced by high fat or HFHF diet (Suanarunsawat et al.,2011; Geetha et al.,2015). It can be seen from the experimental results that HFHF feeding for 12 weeks induces 
oxidative stress to damage the liver, heart, and kidney. Though histopathological investigation was not performed in the present study, our findings can be confirmed by the several previous histological studies. 12 weeks of HFHF diet feeding induced degeneration and necrosis of hepatocytes, intrahepatic hemorrhages, and formation of lipid droplets. (Hazarika et al., 2016.). Degeneration of endomysium and reduced intensity of nuclei was expressed in cardiomyocytes at week 12 of HFHF feeding. Similarly, slightly degenerative changes were apparent at week 12. Even shorter period of HFHF feeding (75 days), lipid accumulation in hepatocytes and impaired renal glomerular capillaries were observed. (Zouari et al., 2016, 2017). Prolonged period of HFHF feeding $(13,16,32$ weeks) produced progressive pathologies of these tissues. (Poudyal et al., 2012; de Castro et al., 2013; Ramli et al., 2014; Hazarika et al., 2016).

TSO treatment restored the high serum levels of AST, ALT, LDH, CK$\mathrm{MB}, \mathrm{BUN}$ and creatinine. It also normalized the high levels of TBARS and low activities of all antioxidant enzymes in both the liver and cardiac tissues. Furthermore TSO normalized TBAR level as well as markedly enhanced both GPx and SOD activities in renal tissue. These reflect that TSO exhibits antioxidative activity to suppress an abundance of tissue free radicals and enhance lowered antioxidant enzymes activities, eventually protected the liver, heart and kidney against HFHF diet feeding.. Vegetable oils enriched in oleic acid have been shown to protect the liver and heart against HFHF diets (Poudyal et al., 2010, 2013). Beside oleic acid, various strong antioxidant ingredients such as phenolic compounds, flavonoids and vitamin E (Fazel et al., 2008; He et al., 2011; Wang et al., 2017) containing TSO would likely account for a great part of the antioxidant properties of TSO to protect various vulnerable organs against HFHF feeding.

\section{CONCLUSION}

The present study demonstrated that HFHF diet feeding for 12 weeks increased blood glucose and serum lipid profiles, and impaired insulin sensitivity. The liver, heart and kidney were also damaged after 12 weeks of HFHF diet feeding. TSO decreased blood glucose, improved insulin sensitivity and suppressed high serum levels of the lipid profile. TSO had free radical scavenging activity which provided liver, cardiac and renal protection against HFHF feeding by suppression of high TBARS level, and enhanced the activities of antioxidant enzymes in these tissues. The oleic acid contained in TSO is possibly responsible for the anti-hyperglycemic, anti-hyperlipidemic and organ protective activities against HFHF diet feeding. 


\section{ACKNOWLEDGEMENTS}

The authors are grateful to acknowledge the Department of Medical Sciences, Faculty of Sciences, Rangsit University for providing the several necessary research facilities to carry out this study.

\section{REFERENCES}

Alkhateeb, H., and Qnais, 2017. E. Preventive effect of oleate on palmitateinduced insulin resistance in skeletal muscle and its mechanism of action. Journal of Physiology and Biochemistry. 73 (5): 605-612. https://doi.org/ 10.1007/s13105-017-0594-9

Chen, J., Li, Q., Zhang, Y., Yang, P., Zong, Y., Qu, S., and Liu, Z. 2011. Oleic acid decreases the expression of a cholesterol transport-related protein (NPC1L1) by the induction of endoplasmic reticulum stress in CaCo-2 cells. Journal of Physiology and Biochemistry. 67(2): 153-163. https://doi. org/10.1007/s13105-010-0058-y

Cheng, Y.T., Lu, C.C., and Yen, G.C. 2015. Beneficial Effects of Camellia Oil (Camellia oleifera Abel.) on Hepatoprotective and Gastroprotective Activities. Journal of Nutritional Science and Vitaminology (Tokyo). 61 Suppl: S100-S102. https://doi.org/10.3177/jnsv.61.S100

Crescenzo, R., Bianco, F., Coppola, P., Mazzoli, A., Tussellino, M., Carotenuto, R., Liverini, G., and Iossa S. 2014. Fructose supplementation worsens the deleterious effects of short-term high-fat feeding on hepatic steatosis and lipid metabolism in adult rats. Experimental Physiology. 99(9): 1203-1213. https://doi.org/10.1113/expphysiol.2014.079632

Daneschvar, H.L., Aronson, M.D., and Smetana, G.W. 2016. FDA-approved anti-obesity drugs in the united states. The American Journal of Medicin. 129 (8): 879.e1-879.e6. https://doi.org/10.1016/j.amjmed.2016.02.009 de Castro, U.G., dos Santos, R.A., Silva, M.E., de Lima, W.G., CampagnoleSantos, M.J., and Alzamora, A.C. 2013. Age-dependent effect of highfructose and high-fat diets on lipid metabolism and lipid accumulation in liver and kidney of rats. Lipids in Health and Disease. 12:136. https://doi. org/10.1186/1476-511X-12-136

Deng, X.L., Xie, G.S., and Huang, S.G. 2002. Study on the health care oil tea and just the function of lipid. China Oils and Fats. 5: 96-98.

Dissard, R., Klein, J., Caubet, C., Breuil, B., Siwy, J., Hoffman, J., Sicard, L., Ducassé, L., Rascalou, S., Payre, B., et al. 2013. Long term metabolic syndrome induced by a high fat high fructose diet leads to minimal renal injury in C57BL/6 mice. PLoS One. 8: e76703. https://doi.org/10.1371/ journal.pone. 0076703 
Fazel, M., Sahari, M.A., and Barzegar, M. 2008. Determination of main tea seed oil antioxidants and their effects on common kilka oil. International Food Research Journal. 15(2): 209-217. https://doi.org/ 10.1016/j.biopha.2016. 09.023

Geetha, R., Radika, M.K., Priyadarshini, E., Bhavani, K., and Anuradha, C.V. 2015. Troxerutin reverses fibrotic changes in the myocardium of high-fat high-fructose diet-fed mice. Molecular and Cellular Biochemistry. 407(1-2): 263-279. https://doi.org/10.1007/s11010-015-2474-3

Hazarika A., Kalita H., Chandra Boruah D., Chandra Kalita M., and Devi R. 2016. Pathophysiology of metabolic syndrome: the onset of natural recovery on withdrawal of a high-carbohydrate, high-fat diet. Nutrition. 32(10): 1081-1091. https://doi.org/10.3945/jn.109.117812

He, L., Guo-ying, Z., Huai-yun, Z., and Jun-ang, L. 2011. Research progress on the health function of tea oil. Journal of Medicinal Plant Research. 5 (4): 485-489.

Huang, C.L., Wu, S.X., Liu, R.X., and Hao, Z.J. 2011. Blood lipid-lowering and fatty liver-preventing effects of tea seed (Camellia oleifera Abel.) oil in rats. Food Science. 32: 332-335.

Kang, J.G and Park, C.Y. 2012. Anti-Obesity Drugs: A review about their effects and safety. Diabetes \& metabolism Journal. 36 (1): 13-25. https://doi.org/ 10.4093/dmj.2012.36.1.1

Kurushima, H., Hayashi, K., Toyota, Y., Kambe, M., and Kajiyama, G. 1995. Comparison of hypocholesterolemic effects induced by dietary linoleic acid and oleic acid in hamsters. Atherosclerosis. 114: 213-221.

Lee, C.P., and Yen, G.C. 2006. Antioxidant activity and bioactive compounds of tea seed (Camellia oleifera Abel.) oil. Journal of Agricultural and Food Chemistry. 54 (3): 779-784.

Lee, C.P., Shih, P.H., Hsu, C.L., and Yen, G.C. 2007. Hepatoprotection of tea seed oil (Camellia oleifera Abel.) against CCl4-induced oxidative damage in rats. Food and Chemical Toxicology. 45 (6): 888-895.

Lee, J.S, Jun, D.W., Kim, E.K., Jeon, H.J., Nam, J.H., Saeed, and W.K. 2015. Histologic and metabolic derangement in high-fat, high-fructose, and combination diet animal models. The Scientific World Journal. 2015: 306326. https://doi.org/10.1155/2015/306326

Lowry, O.H., Rosebrough, N.J., Farr, A.L., and Randall, R.J. 1951. Protein measurement with the Folin phenol reagent. The Journal of Biological Chemistry. 193 (1): 265-275.

Lozano, I., Van der Werf, R., Bietiger, W., Seyfritz, E., Peronet, C., Pinget, M., Jeandidier, N., Maillard, E., Marchioni, E., Sigrist, S., and Dal, S. 2016. High-fructose and high-fat diet-induced disorders in rats: impact on diabetes risk, hepatic and vascular complications. Nutrition and Metabolism (Lond). 13: 15. https://doi.org/10.1186/s12986-016-0074-1. 
Luck, H. 1965. Catalase. In Bergmeyer, H.U., editor. Method for enzymatic analysis. New York and London: Academic Press. p. 885-888.

McCracken, E., Monaghan, M., and Sreenivasan, S. 2018. Pathophysiology of the metabolic syndrome. Clinics in Dermatology. 36(1): 14-20. https://doi. org/10.1016/j.clindermatol.2017.09.004

Misra, A. and Khurana, L. 2008. Obesity and the metabolic syndrome in developing countries. The Journal of Clinical Endocrinology and Metabolism. 93 (11 Suppl 1): S9-S30.

Nasri, R., Abdelhedi, O., Jemil, I., Daoued, I., Hamden, K., Kallel, C., Elfeki, A., Lamri-Senhadji, M., Boualga, A., Nasri, M., et al. 2015. Ameliorating effects of goby fish protein hydrolysates on high-fat-high-fructose dietinduced hyperglycemia, oxidative stress and deterioration of kidney function in rats. Chemico-Biological Interactions. 242: 71-80. https://doi. org/10.1016/j.cbi.2015.08.003

Ohkawa, H., Ohishi, N., and Yagiv, K. 1979. Assay for lipid peroxides in animal tissues by thiobarbituric acid reaction. Analytical Biochemistry. 9(2): 351358. https://doi.org/10.1016/0003-2697(79)90738-3

Ping, W., Chunrong, W., Jian, Z., and Wenxun, F. 1993. Effect of tea seed oil on blood lipid and platelet function in animals. Acta Nutri Sin Acta Nutrimenta Sinica. 4: 377-384.

Poudyal, H., Campbell, F., and Brown, L. 2010. Olive leaf extract attenuates cardiac, hepatic, and metabolic changes in high carbohydrate-, high fat-fed rats. The Journal of Nutrition. 140(5): 946-953. https://doi.org/10.3945/ jn.109.117812

Poudyal, H., Pancha, S.K., Ward, L.C., Waanders, J., and Brown L. 2012. Chronic high-carbohydrate, high-fat feeding in rats induces reversible metabolic, cardiovascular, and liver changes. American Journal of Physiology-Endocrinology and Metabolism. 302(12): E1472-E1482. https://doi.org/110.1152/ajpendo.00102.2012

Poudyal, H., Kumar, S.A., Iyer, A., Waanders, J., Ward, L.C., and Brown, L. 2013. Responses to oleic, linoleic and $\alpha$-linolenic acids in highcarbohydrate, high-fat diet-induced metabolic syndrome in rats. The Journal of Nutritional Biochemistry. 24(7): 1381-1392. https://doi.org/10. 1016/j.jnutbio.2012.11.006

Ramli, N.S., Brown, L., Ismail, P., and Rahmat, A. 2014. Effects of red pitaya juice supplementation on cardiovascular and hepatic changes in highcarbohydrate, high-fat diet-induced metabolic syndrome rats. BMC Complementary and Alternative Medicine. 14: 189. https://doi.org/10. 1186/1472-6882-14-189

Shen, T.T., and Wu, S.X. 2017. Effects of tea seed oil on hyperlipidemic rats induced by high-fat diet. Food Science and Technology Research. 23 (1): 101-109. 
Suanarunsawat, T., Ayutthaya, W.D., Songsak, T., Thirawarapan, S., and Poungshompoo, S. 2011. Lipid-lowering and antioxidative activities of aqueous extracts of Ocimum sanctum L. leaves in rats fed with a high-cholesterol diet. Oxidative Medicine and Cellular Longevity: 962025. https://doi.org/10.1155/2011/962025

Tapple, A.L. 1978. Glutathione peroxidase and hydroperoxidase methods. In Sidney, F., and Lester, P. editors. Methods in enzymology Vol II. New York: Academic Press. p. 506-513.

Wang, X., Zeng, Q., Del Mar Contreras, M., and Wang, L. 2017. Profiling and quantification of phenolic compounds in Camellia seed oils: natural tea polyphenols in vegetable oil. Food Research International. 102: 184-194. https://doi.org/10.1016/j.foodres.2017.09.089

Winterbourn, C.C., Hawkins, R.E., Brian, M., and Carrell, R.W. 1975. The estimation of red cell superoxide dismutase activity. Journal of Laboratory and Clinical Medicine. 85 (2): 337-341.

WHO. 2003. Diet, nutrition and the prevention of chronic diseases: report of a Joint WHO/FAO Expert Consultation. WHO Technical Report Series, No.916 (TRS 916). Available from http://www.who.int/dietphysicalactivity/ publications/trs916/en/

WHO. 2015. Sugars intake for adults and children Guideline. Available from http://www.who.int/nutrition/publications/guidelines/sugars_intake/en/

Xiao, X., He, L., Chen, Y., Wu, L., Wang, L., and Liu, Z. 2017. Antiinflammatory and antioxidative effects of Camellia oleifera Abel components. Future Medicinal Chemistry. 9(17): 2069-2079. https://doi. org/10.4155/fmc-2017-0109

Yang, F., Zhang, Y., Xu, Q., Li, R., Yang, X., Liu, Y., Wang, J., Yu, X., and Xue, C. 2013. Effects of oils on lipid metabolism in obese C57BL/6J mice induced by a high fat diet. Wei Sheng Yan Jiu. 42 : 901-6, 914.

Ziv, E., Patlas, N., Kalman, R., Pelled, D., Herzog, Y., Dror, T., and Cohen, T. 2009. A high oleic sunflower oil fatty acid esters of plant sterols mixed with dietary diacylglycerol reduces plasma insulin and body fat accumulation in Psammomys obesus. Lipids in Health and Disease. 8:42. 10.1186/1476-511X-8-42. https://doi.org/10.1186/1476-511X-8-42

Zouari, R, Hamden, K., Feki, A.E., Chaabouni, K., Makni-Ayadi, F., Kallel, C., Sallemi, F., Ellouze-Chaabouni, S., and Ghribi-Aydi. D. 2016. Protective and curative effects of Bacillus subtilis SPB1 biosurfactant on high-fathigh-fructose diet induced hyperlipidemia, hypertriglyceridemia and deterioration of liver function in rats. Biomedicine and Pharmacotherapy. 84: 323-329. https://doi.org/10.1016/j.biopha.2016.09.023 
Zouari, R., Hamden, K., El, Feki, A., Chaabouni, K., Makni-Ayadi, F., Sallemi, F., Ellouze-Chaabouni, S., and Ghribi-Aydi, D. 2017. Evaluation of Bacillus subtilis SPB1 biosurfactant effects on hyperglycemia, angiotensin I-converting enzyme (ACE) activity and kidney function in rats fed on high-fat-high-fructose diet. Archives of Physiology and Biochemistry. 123(2): 112-20. https://doi.org/10.1080/13813455.2016.1261902 